\title{
A TRAVESSIA DE ESCRAVOS DOS SERTÕES DE ANGOLA PARA OS SERTÕES DE PERNAMBUCO (1750-1810)
}

\author{
Alexandre Bittencourt Leite Marques*
}

\begin{abstract}
RESUMO:A presença de escravos originários da África era uma constante na trajetória do escravismo nos sertões de Pernambuco, sobretudo a partir da segunda metade do século XVIII. Consolidadas as fazendas de gado, erigidos povoados e vilas e cultivadas as plantações de algodão, potencializou-se muito mais a presença de escravos provenientes de algumas partes da África, principalmente de Angola. Apesar disso, há uma carência de estudos sobre a introdução forçada desses escravos africanos e de seus descendentes nos ditos sertões de Pernambuco. Nesse sentido, o presente trabalho tem por objetivo analisar a saída de escravos dos sertões de Angola até suas inserções nos sertões de Pernambuco, procurando contribuir no preenchimento de algumas lacunas a respeito do estudo da escravidão no interior pernambucano.
\end{abstract}

PALAVRAS-CHAVES: Escravos; Sertões de Pernambuco; Sertões de Angola.

\section{The slave crossing from the hinterlands of Angola to the hinterlands of Pernambuco (1750-1810)}

ABSTRACT: The presence of slaves from Africa was a constant in the trajectory of slavery in the hinterland of Pernambuco, especially since the second half of the eighteenth century. The consolidation of cattle farms, settlements, and the cultivation of cotton plantations greatly increased the presence of slaves from some parts of Africa, mainly Angola. Nevertheless, there is a lack of studies about the forced penetration of these African slaves and their descendants in the so-called backlands of Pernambuco. Thus, this work aims to analyze the departure of slaves from the hinterlands of Angola to Pernambuco, seeking to contribute to fulfill some gaps some gaps about the study of slavery in Pernambuco countryside.

KEYWORDS: Slaves; Hinterlands of Angola; Hinterlands of Pernambuco.

\section{El cruce de esclavos desde el interior de Angola hasta el interior de Pernambuco (1750-1810)}

RESUMEN: La presencia de esclavos originarios de África fue una constante en la trayectoria de la esclavitud en la tierra adentro de Pernambuco, especialmente a partir de la segunda mitad del siglo XVIII. La consolidación de granjas ganaderas, asentamientos y aldeas y el cultivo de plantaciones de algodón aumentaron en gran medida la presencia de esclavos de algunas partes de África, principalmente Angola. Sin embargo, faltan estudios sobre la introducción forzada de estos esclavos africanos y sus descendientes en las llamadas tierras remotas de Pernambuco. En este sentido, el presente trabajo tiene como objetivo analizar la partida de los esclavos de las tierras adentro de Angola a sus inserciones en las zonas del interior de Pernambuco, tratando de contribuir a llenar algunos vacíos sobre el estudio de la esclavitud en la tierra adentro de Pernambuco

PALABRAS CLAVE: Esclavos; Tierra adentro de Pernambuco; Tierra adentro de Angola.

\footnotetext{
*Doutor em História pela Universidade de Évora, Portugal. Atualmente é pesquisador integrado ao Centro de História da Universidade de Lisboa. Contato: Alameda da Universidade, Cidade Universitária, CEP: 1649-004, Lisboa, Portugal. E-mail: alexandre.bittencourt@hotmail.com. ORCID: https://orcid.org/0000-0002-8441-5259.
} 
A historiografia está bem servida de trabalhos que se dedicam a analisar o comércio de escravos na África e as remessas que saíam de lá para o Atlântico. ${ }^{1}$ No que corresponde a Angola, por exemplo, David Birmingham, Joseph Miller, John Thornton, Maria Emília Madeira, Maria do Rosário Pimentel, Roquinaldo Ferreira, Luiz Felipe de Alencastro e Mariana Cândido são alguns dos investigadores que abordam esse tema. Se, por um lado, sobre Angola, há uma lista de estudos que tratam da descida dos escravos dos sertões para os portos de Luanda e Benguela (de onde saíam para a travessia atlântica), o mesmo não pode ser dito em relação à entrada de parte desses escravos nos portos marítimos de Pernambuco e, menos ainda, em relação à penetração desses recém-chegados cativos em direção ao interior da antedita capitania da América portuguesa ao longo do século XVIII. ${ }^{2}$

A respeito do termo sertão (plural sertões), apropriamos-nos dos significados encontrados nos dicionários de época, por exemplo, o de Raphael Bluteau (1728) e Antonio de Moraes Silva (1789). Em Bluteau, o termo é conceituado da seguinte forma: "região, apartada do mar, e por todas as partes, metida entre terras. Mediterranea Regio". ${ }^{3}$ Em Moraes Silva, lemos: "o interior, o coração das terras, opõe-se ao marítimo, e costa. O sertão toma-se por mato longe da costa". ${ }^{4}$ Dessa forma, os núcleos coloniais do nosso recorte geográfico inserem-se justamente nesse sentido do termo sertão, já que se localizavam no interior do território de Pernambuco e de Angola. ${ }^{5}$

Na historiografia de Pernambuco, pouco são os estudos que se debruçaram sobre os detalhes do transporte dos escravos africanos e descendentes que adentravam o litoral em direção ao interior. Alguns fatores contribuíram para isso, dentre eles, maior interesse dos investigadores em analisar a escravidão no mundo do açúcar, isto é, nas áreas do litoral e entorno. Isso fez com que fossem desviadas as atenções dos estudos da presença escrava nos sertões. Outro fator se refere também à existência de parcas informações nas fontes de pesquisa sobre os trajetos de escravos no interior de Pernambuco, o que dificulta o trabalho a respeito do dito recorte geográfico. Contudo, apesar de escassos e pontuais, esses indícios existem e podem ser encontrados mediante análises minuciosas na documentação. Quando trabalhados, esses indícios contribuem para o preenchimento das lacunas a respeito desse tema.

Na segunda metade do século XVIII, o militar cronista Elias Alexandre da Silva Corrêa escreveu a respeito dos momentos de chegada dos escravos (provenientes do interior africano) ao porto marítimo de Luanda, e da reação desencadeada nos diversos comerciantes que estavam à espera: “chegam por pelotões às remessas dos Sertões: todos correm as 
compras dos seus cativos receando a demora de outros por muitos obstáculos." Os escravos eram o gênero comercial mais exportado naquela colônia africana. Segundo o referido cronista, do outro lado do Atlântico, havia três portos no Brasil que mais importavam esses escravos procedentes de Angola: eram os do Rio de Janeiro, Bahia e Pernambuco. De acordo com Corrêa, uma vez desembarcados nesses três lugares, essas pessoas cativas se espalhavam para os diversos sertões e demais capitanias da América portuguesa. ${ }^{6}$

Esses escravos ocuparam o papel de principal mercadoria remetida de Angola para a América portuguesa, à frente do marfim, da cera, do ferro e dos animais selvagens. Era a mercadoria principal que aglutinava em seu bojo todas as outras anteditas. Além disso, dentre todas essas mercadorias, sem dúvida, foi a que mais exerceu influência cultural na sociedade colonial. No século XVIII, acostumados a trabalhar na criação de gado e plantação de mandioca e milho nos antigos territórios que habitavam na África, muitas vezes, esses escravos eram adquiridos por senhores dos sertões de Pernambuco e adjacências. ${ }^{7}$ Ali, aplicavam diversas práticas e costumes vindos da África, bem como se miscigenavam biológica e culturalmente com a população local composta por colonizadores europeus (sobretudo portugueses) e grupos indígenas.

A organização do tráfico atlântico de escravos na África começou a ser feita desde cedo, já no século XVI. De acordo com Alencastro, basicamente os africanos transportados ao Brasil vieram de duas áreas principais: uma formada pela Baía de Benim e pelo golfo de Biafra, e a outra localizada no Centro-Oeste africano, sobretudo em Angola. Os grandes portos negreiros situavam-se nas principais bacias hidrográficas, como a do rio Congo e Quanza (Congo-Angola), propiciando o transporte fluvial de escravos do interior da África até os portos marítimos da costa africana. Do outro lado do Atlântico, os primeiros desembarques desses cativos africanos foram em Pernambuco, uma das capitanias do Brasil, entre os anos de 1550 e 1560. Do século XVI até 1850, o Brasil foi o maior importador de escravos africanos das Américas. ${ }^{8}$

Em relação especificamente à ida de escravos africanos para Pernambuco, segundo Suely Almeida e Jéssica de Souza, os cativos partiam da Costa da Mina na África Ocidental, assim como de Angola na África Centro-Ocidental. Contudo, em meados do século XVIII, com a instituição da Companhia Geral de Pernambuco e Paraíba, as rotas comerciais que abasteciam o mercado de Pernambuco de cativos vindos da Costa da Mina "serão redirecionadas para Angola, agindo em consonância ao conjunto de medidas adotadas pela Coroa a partir de 1730 para impulsionar o comércio de escravos na região da África Centro- 
Ocidental". Como resultado desse advento, a partir do supracitado período, para Pernambuco haverá um aumento significativo de escravos provenientes de Angola, e uma redução considerável de escravos emanados da Costa da Mina. ${ }^{9}$

De acordo com Roquinaldo Ferreira, na África Centro-Ocidental, os embarques de escravos eram direcionados, sobretudo, ao Brasil. Apesar da distância espacial entre um e outro, havia facilidades de contatos marítimos favorecidos por correntes e regimes de ventos. A interação direta de Angola com Brasil, por exemplo, estimulou a economia do tráfico atlântico. Boa parte do tráfico dependia de redes comerciais e logísticas que eram, em grande parte, controladas a partir do Brasil. ${ }^{10}$ Inclusive, conforme já referido, nos últimos anos, a historiografia vem debruçando-se nessas fortes ligações bilaterais entre um e outro. Como dito por Alencastro, "95\% das viagens que desembarcaram africanos nos portos brasileiros foram iniciadas nesses mesmos portos, sobretudo no Rio de Janeiro, na Bahia e em Recife (nessa ordem)". ${ }^{11}$

Em Angola, oficialmente havia duas formas de comercializar os escravos retirados para o Brasil. Uma era por meio da participação direta da Coroa com seus feitores, já a outra era mediante direitos concedidos pela Coroa para armadores e mercadores por contrato. Desde o século XVI em diante, a Coroa Portuguesa legislou sobre esses direitos ora liberando mais a atuação desses particulares, ora reduzindo mais essas atuações. No início da segunda metade do século XVIII, houve a criação da Companhia do Maranhão e Grão-Pará (1755) e da Companhia de Pernambuco e Paraíba (1759). ${ }^{12}$ Especificamente a respeito desta última, um grupo de mercadores de Lisboa, Porto e de Pernambuco solicitou à Coroa, em 1759, autorização para estabelecer uma companhia para as capitanias de Pernambuco e Paraíba. ${ }^{13}$

A ideia da criação de companhias que tivessem por objetivos o fornecimento de escravos ao Brasil fazia parte das intenções da Coroa e dos seus altos funcionários. Entretanto, o estabelecimento dessas companhias não pôs fim ao tráfico realizado pelos particulares brasileiros. Concomitantemente, o tráfico negreiro permaneceu ativo, sobretudo no fim do século, quando as companhias deixaram de fornecer escravos ao Brasil. Isso para não falarmos também dos contrabandos e descaminhos de escravos que nunca deixaram de ocorrer ao longo dos séculos entre as duas colônias. ${ }^{14}$

No âmbito dos diversos estudos sobre o comércio de escravos em Angola, muito se falou sobre o processo de obtenção dos cativos e sobre as mercadorias comumente usadas nesses resgates, como matérias-primas e produtos manufaturados. Algumas das mercadorias eram obtidas em diferentes regiões africanas (sal, cola, anil, algodão, por exemplo), já outras 
eram originadas da América (jeribitas, tabaco, dentre outros), Europa (armas, pólvora, chapéus, vestimentas, bengalas, e outros artigos.) e até da Ásia (como os tecidos da índia.). Inseridos a partir dos portos de Luanda e Benguela, esses produtos eram negociados por escravos e se espalhavam pelos sertões adentro. Em contrapartida, caravanas de escravos desciam dos sertões em direção à costa para serem remetidas, principalmente, para o Brasil. Esses produtos eram essenciais para aquisição de escravos. No ano de 1784, por exemplo, a Coroa Portuguesa ordenou que os gêneros de Portugal, das ilhas adjacentes e do Brasil (especificamente: aguardente, tabaco, jeribita e outro licor forte) que se destinavam àquele comércio escravista não pagassem "Direitos alguns de Entrada, nem outra alguma imposição qualquer ela que seja". O intuito era "favorecer" e "animar" o comércio escravista no sertão de Angola ${ }^{15}$.

Os escravos eram conduzidos por diversas rotas que interligavam os sertões da África aos principais portos litorâneos. Na África Centro-Ocidental, por exemplo, as vastas redes comerciais (que partiam do litoral de Luanda, Benguela e Ambriz até a periferia da penetração portuguesa) acabavam por estabelecer a ligação do interior à economia atlântica. Ao longo dos caminhos, entrepostos, presídios, feiras, paróquias foram erigidos e proporcionaram cada vez mais a penetração em direção aos lugares mais distantes. Núcleos urbanos instituídos tanto no litoral, quanto nos sertões de Angola: Luanda, Cassange, Pungo Andongo, Benguela, Caconda, Ambaca e Bié, serviram de pontos para os colonizadores lançarem muito mais a penetração portuguesa nas extremas distâncias do interior do continente africano. ${ }^{16}$

A Feira de Cassange, por exemplo, localizada no "distante sertão tão complicado e dependente", era considerada pelas autoridades de Angola como "a mais principal e base fundamental da exportação dos escravos deste Reino [Angola]" para as Praças de Lisboa e Brasil. ${ }^{17}$ No século XVII, vitórias militares afirmariam a presença portuguesa na região de Cassange tanto no pano comercial quanto no militar. ${ }^{18}$ De Cassange e de outros pontos dos sertões, esses indivíduos percorriam centenas de quilômetros de caminhos de terra, presos em ferros uns aos outros, até chegarem aos portos marítimos da África Centro-Ocidental (Luanda, Cabinda, Benguela). ${ }^{19}$ Apesar de parte dos escravos serem capturados e transportados dos mais diversos e distantes sertões da África Centro-Ocidental, vale recordar que nem todo cativo embarcado era originário exclusivamente do mais longínquo interior (como os que vinham do reino dos Lundas), havia também muitos indivíduos reduzidos à escravidão, que eram habitantes das áreas do litoral e sertões mais ou menos próximos de Luanda, ou seja, das 
áreas de domínio/influência portuguesa (Benguela, Muxima, Massangana, Icollo, Cambambe, Pedras, Ambaca, Cassange, e demais lugares).

A condução de escravos entre os sertões e o litoral da África era cansativo, tortuoso e perigoso para esses cativos. Talvez um dos relatos mais tristes sobre a travessia terrestre de escravos, do centro à costa, seja o do médico e explorador escocês Mungo Park (1771-1806), escrito entre os últimos anos do século XVIII e primeiros anos do XIX na África Ocidental.

\footnotetext{
Ordinariamente os seguram [escravos] pondo a perna esquerda d'um, e a direito doutro em um mesmo par de ferros que pendurados de uma corda os deixam caminhar, posto que muito devagar. Cada quatro escravos vão atados também pelo pescoço com correias retorcidas; pela noite se atam as mãos com anéis de ferro, e algumas vezes se põem uma cadeia de ferro ao pescoço. ${ }^{20}$
}

Numa das cenas que presenciou, Mungo Park descreveu o trágico fim de uma escrava. Após a caravana de cativos andar por "um mato escabroso" que molestava muito os pés, uma escrava, de nome Nili, queixou-se de muitas dores nas pernas. Para piorar a situação, mais adiante, toda a gente foi cercada por um enxame de abelhas, sendo a referida escrava a mais atacada por não ter forças para fugir. "As abelhas a puseram feito um monstro", disse Park. Após caminhar por mais cinco horas, sem condições de continuar, montaram-na num burro, mas estava tão fraca que não conseguiu segurar-se no animal. Passou, então, a ser carregada pelos outros escravos. No dia seguinte, a escrava "tinha todos os seus membros tão pasmados e dolorosos, que não podia se conter em pé". Em outra tentativa falha de pô-la na besta, caiu novamente na terra "com uma perna horrivelmente mal tratada". Após tudo isso, Nili foi abandonada pela caravana no meio de um campo onde, de acordo com Mungo Park, "seguramente morreria bem cedo ou seria devorada pelas feras". 21

Embora Park tenha presenciado e se referido sobre a travessia terrestre de escravos de regiões da África Ocidental, podemos inferir que o processo penoso não deveria ser tão diferente em partes da África Centro-Ocidental, isto é, em Angola, Benguela e Congo, também na passagem do século XVIII para o XIX. Além disso, o percurso dos cativos nas longas distâncias dos sertões da África para o litoral angolano era só o início do sofrimento por que passavam esses homens, mulheres e crianças. As condições precárias dessas pessoas continuavam ou, até mesmo, pioravam ao serem embarcadas nos portos africanos. Os atrasos dos navios nos portos bem como a superlotação contribuíam para que muitos morressem antes mesmo que os navios levantassem âncora. ${ }^{22}$

Além disso, ao longo da travessia do Atlântico, mais escravos pereciam confinados nas embarcações. Como presenciado e descrito pelo cronista Elias Alexandre da Silva Corrêa, 
militar que serviu em Angola na segunda metade do século XVIII, a demora na saída de um navio destinado a Pernambuco, por exemplo, causou a morte de 104 cabeças de escravatura, que sucumbiram da doença chamada "bexiga" no ano de 1786. Em outra ocasião, o cronista militar militar descreveu a morte de escravos numa viagem que fez de Angola para o Rio de Janeiro, com escala na capitania do Espírito Santo. A farinha de mandioca servida a esses escravos estava podre e cheia de bichos, o que causou uma terrível epidemia e muitas mortes. Também viu morrer pelos rigores do frio e chuva uma "negrinha" que não conseguiu alojar-se em algum lugar coberto da embarcação, assim como um negro moribundo lançado ainda vivo do navio ao mar. Portanto, percebe-se que as travessias eram tanto penosas quanto mortais.

Devido a essas péssimas condições, por vezes, havia revoltas dos escravos que seguiam dos sertões da África Centro-Ocidental em direção às Américas. Segundo um relato escrito em 1782 por Antônio José Pimentel Castro de Mesquita, governador de Benguela, mesmo presos, os escravos dos sertões de Benguela conseguiam fazer frequentes levantes. Para esse governador, o mesmo não ocorria com os escravos dos sertões de Angola que, por serem "frouxos", iam todos soltos rumo à América. Isso era explicado por Mesquita pelo fato de Angola possuir nove presídios (fortalezas). Diferentemente de Benguela, que possuía somente Caconda e, mesmo assim, este era subordinado a Angola. ${ }^{23}$ Nesse sentido, o relato dá a entender que os escravos dos sertões que possuíam presídios se caracterizavam como dóceis. Já aqueles cativos originados dos sertões sem presídios, caracterizavam-se como revoltosos. Dessa forma, podemos inferir que a presença dessas fortalezas contribuía para o processo de disciplina e repressão sobre os escravos que seriam transportados dali e embarcados para o continente americano.

O tráfico de escravos pelo Atlântico era feito através de uma complexa rede formada por diferentes tipos de indivíduos espalhados tanto na África, quanto na América e Europa. Essas pessoas exerciam as mais variadas funções e desempenhavam papéis essenciais para o funcionamento da rede. Sendo assim, procuramos identificar trechos da trajetória de alguns agentes que, direta ou indiretamente, estavam inseridos numa ampla rede desse tráfico negreiro que seguia no sentido leste-oeste, especificamente, de Angola para Pernambuco.

No sertão de Cassange, em Angola, por exemplo, o diretor da feira e negociante de nome Francisco Honorato possuía contas e relações comerciais com diversos credores e procuradores, dentre eles, Manuel Gomes dos Santos (de Pernambuco) e Hermenegildo Neto (da Bahia). O nome desses indivíduos e de outros negociantes apareceu num extrato de contas de operações realizadas em 1794 e 1795, o que demonstra que existiam vínculos entre pessoas 
de variados lugares, inclusive de Pernambuco, com o tal negociante de escravos e marfim no referido sertão angolano. ${ }^{24}$

Por falar na feira de Cassange, identificamos em outro documento que um "cigano" de Pernambuco foi uma das várias pessoas responsáveis por enviar as caravanas de escravos da dita feira e de outros sertões para a costa de Angola. Consta nos autos que o "cigano" Manoel de Faria Marinho era "natural de Pernambuco, de onde veio voluntariamente negociar neste Reino [de Angola]", como feirante legitimado pela Junta de Comércio para ter acesso à Feira de Cassange, onde negociava escravos e outras mercadorias. ${ }^{25} \mathrm{O}$ fato de Manoel ter nascido em Pernambuco, uma das principais capitanias do Brasil a receber escravos oriundos de Angola, pode sugerir-nos o interesse que levou o Manoel a empreender viagem e realizar seus negócios naquela colônia portuguesa na África.

O fato de ser descrito como um indivíduo que foi voluntariamente negociar em Angola nos revela que Manoel não era um degradado da Coroa, mas sim um negociante que, por conta própria, foi àquelas paragens, onde chegou a constituir patrimônio, como alguns escravos, produtos e outros bens que se encontravam na jurisdição da fortaleza de Ambaca, também nos sertões angolanos. ${ }^{26}$ Os produtos comerciais adquiridos nos sertões de Angola pelo "cigano" Manoel eram escravos, marfim, ceras e outras "fazendas". Para aquisição desses produtos, Manoel fazia uso de dinheiro e jeribita, aguardente feita da cana-de-açúcar. ${ }^{27}$ Por sinal, é bom salientar que a jeribita que ia para Angola era produzida no Brasil, inclusive em Pernambuco. $^{28}$

Manoel não era um novato em terras angolanas. Segundo consta nos autos, o "cigano" informou que estava acostumado a percorrer os caminhos dos sertões de Angola havia muitos anos, onde realizava seus negócios. Lugares como Luanda, Benguela Ambaca, Cassange, Haco, Golungo, entre outros aparecem na documentação como áreas ou caminhos que o “cigano" de Pernambuco percorria em seus trajetos entre o litoral e os sertões de Angola. Ao que parece, uma das rotas que fazia era de Luanda, no litoral, em direção à feira de Cassange nos sertões. Na volta para Luanda, já carregado de escravos e outras mercadorias, ainda parava antes por Ambaca e Golungo, localizados entre Cassange e Luanda. ${ }^{29}$

As experiências ao longo desses anos e lugares por onde passou renderam ao cigano contatos e sociabilidade com diversas pessoas naquelas paragens. Manoel alegava possuir um "aviante (credor) na capital Luanda, chamado Manoel da Cruz, do qual recebia dele "sortimentos" ou "carregação" para seguir para a feira de Cassange, no sertão, e depois retornar com escravos e demais fazendas à Luanda para o acerto de pagamento com o dito 
“aviante”. Além desse último, Manoel também fez referência a outros feirantes da praça daquela colônia, assim como a pessoas do poder local, por exemplo, um capitão-mor do Distrito de Golungo, chamado Vicente Rodrigues Fialho. Por fim, o nome de outros indivíduos que apareceram nos autos nos revelam que a rede de sociabilidade de Manoel de Faria Marinho envolvia também outros ciganos feirantes que tinham participação no comércio dos sertões de Angola. ${ }^{30}$

A presença de pessoas oriundas de Pernambuco e de outros lugares do Brasil nos sertões de Angola não era de se estranhar. Por vezes, o próprio governo da referida colônia solicitava a ida de colonos e soldados do Brasil para lá no intuito de servirem e povoarem aquele território. ${ }^{31}$ No ano de 1790, o governador de Angola comentava sobre a ida de escravos da África para o Brasil. Em troca da entrada de escravos, o dito governador desejava a vinda de militares do Brasil para África:

Que os naturais da Zona Tórrida eram os mais análogos a viver nella, ou seja, na
América, ou na África, e que recebendo o Rio, Bahia e Pernambuco tantos braços
[escravos] de Angola com que desfrutavam os efeitos do Brasil, lhe parecia justo
que os generais respectivos [governadores-generais do Brasil] tivessem ordem de
socorrer aquele Reino [Angola] e de fornecerem anualmente com cento e cinquenta,
ou cem homens de recruta daqueles muitos ociosos e vadios de que a República quer
expurgasse, e que ele conhecera nas referidas Cidades, além dos sentenciados e
criminosos

Em 1796, novamente falava-se na necessidade de entrada de pessoas do Brasil em Benguela. Dessa vez, o governo solicitava 80 casais de pardos retirados do Rio de Janeiro, Bahia e Pernambuco, por melhor se conservarem na África, no intuito de aumentar a população. O objetivo era que esses homens entrassem para servir como soldados, mas depois, pelas suas "agências, industriais ou ofícios", se tornassem "capazes de se estabelecerem e negociarem", sendo dada baixa do serviço militar, por ser mais útil um negociante. ${ }^{33}$

Inclusive, na África Centro-Ocidental, havia uma espécie de preferência para que essas pessoas fossem oriundas dos sertões de Pernambuco e da Bahia que, segundo tese da época, seriam mais acostumados com o clima dos sertões de Angola. Nos anos de 1735 e 1736, por exemplo, houve solicitação de homens não só dos sertões de Pernambuco, dos da Bahia (Brasil), como também do Alentejo e Algarve (Portugal). A justificativa era a seguinte: "por serem de terras mais quentes aturam o trabalho" em Angola. ${ }^{34}$

Não sabemos quantas entradas se deram e quantos desses homens do Brasil (militares e/ou negociantes) se tornaram residentes em solo de Angola. Contudo, sabe-se que as 
solicitações feitas pelo governo de Angola existiram e algumas delas se concretizaram. O cigano Manoel de Faria Marinho certamente era um exemplo de comerciante que se estabeleceu nos sertões daquela colônia em África, onde passou a negociar escravos. Por sua vez, outra personagem que identificamos envolvido no tráfico de escravos de Angola para Pernambuco foi o mestre de campo da Praça do Recife, chamado João Oliveira Gouvin. ${ }^{35}$ Contudo, parece que o mestre de campo não adentrou Angola, diferentemente do cigano Manoel.

Gouvin fazia parte de uma elite local em Pernambuco, e sua interlocução com Angola era a partir de outras esferas. Em busca de fragmentos de sua atuação no tráfico, identificamos num ofício do Conselho Ultramarino que Gouvin declarou ter feito remessa de dinheiro por ordem dos administradores do Contrato da saída dos escravos de Angola no ano de $1766 .{ }^{36}$ Por sua vez, no Livro da Casa Comercial de Luanda, localizado no ANTT, há informações de que João de Oliveira Gouvin era de Pernambuco, e possuía uma conta corrente na Casa Comercial em Luanda. Gouvin parecia representar a direção da dita Companhia, tendo como função pagar as remessas de escravos que iam de Angola para Pernambuco. ${ }^{37}$ Identificamos também que o personagem mantinha interlocução com o provedor de Pernambuco João do Rego Barros. ${ }^{38}$ Por diversas vezes o nome de Gouvin apareceu relacionado com a Companhia de Comércio de Pernambuco e aos Direitos de Saída dos Escravos de Luanda para aquela capitania da América portuguesa entre os anos de 1763 e 1765 (Quadro 1).

Quadro 1: Participação de João de Oliveira Gouvin, Mestre de Campo do Recife, em algumas saídas de escravos de Angola para Pernambuco, 1763-1765.

\begin{tabular}{|l|l|l|}
\hline Data & Número de escravos & \multicolumn{1}{c|}{ Embarcação } \\
\hline 23 de julho de 1763 & 350 cabeças & Corveta Nossa Senhora da Guia \\
10 de janeiro de 1764 & 400 cabeças & $\begin{array}{l}\text { Corveta Santíssimo Sacramento e Todos os Santos, } \\
\text { capitão Aleixo de Araújo }\end{array}$ \\
26 de março de 1764 & 521 cabeças & $\begin{array}{l}\text { Corveta Santo Antônio, de quem é capitão Roque } \\
\text { Jacinto }\end{array}$ \\
4 de agosto de 1764 & 351 cabeças & $\begin{array}{l}\text { Corveta Nossa Senhora da Guia, de quem é capitão } \\
\text { Manoel Pereira }\end{array}$ \\
8 de julho de 1765 & 350 cabeças & $\begin{array}{l}\text { Corveta Nossa senhora da Guia, capitão Manoel } \\
\text { Pereira }\end{array}$ \\
8 de julho de 1765 & $\begin{array}{l}\text { 422 cabeças e 13 } \\
\text { crias }\end{array}$ & $\begin{array}{l}\text { Corveta Nossa Senhora do Rozário, Santo Antônio } \\
\text { e Almas, capitão Antônio Roiz dos Santos }\end{array}$ \\
\hline
\end{tabular}

Fonte: ANTT. Feitos Findos, Livros dos Feitos Findos, liv. 62. PT/TT/LFF/0062. 
Como podemos observar no Quadro 1, João de Oliveira Gouvin estava envolvido em significativos despachos de cativos de Angola para Pernambuco. Diferentemente do cigano Manoel de Faria Marinho, o dito Gouvin fazia parte de um círculo mais elitizado em termos dos negócios de escravos. O cigano de Pernambuco participava do tráfico terrestre e realizava um árduo trabalho em percorrer os distantes e perigosos sertões de Angola em busca de escravos para levar até o porto de Luanda. Já o mestre de campo do Recife, era um dos responsáveis pela movimentação de dinheiro da Companhia de Comércio de Pernambuco, tendo seu nome atrelado ao tráfico transatlântico entre Angola e a referida capitania da América portuguesa. Talvez essas duas personagens nunca tenham se encontrado ao longo dos anos, afinal, quase 40 anos separam as informações que temos sobre um e outro. Porém, ambas tinham em comum o fato de serem de Pernambuco e de fazerem parte da engrenagem do transporte de escravos de Angola para o Brasil, cada qual exercendo seu papel específico nesse tráfico de seres humanos.

A presença de outros nomes ao lado de Gouvin, no Livro da Casa Comercial de Luanda, também nos chamou a atenção. No exercício de sua função, Gouvin parece ter-se relacionado (não sabemos se presencialmente ou a distância) com diversas pessoas moradoras em Angola ou que transitavam entre o Brasil e África. Sobre esses últimos, tratava-se dos capitães responsáveis pelas embarcações e dos padres capelães que seguiam nas ditas embarcações com a função de ministrar os sacramentos do catolicismo para os escravos. Além disso, observamos que, ao fazerem essas travessias pelo Atlântico, essas pessoas não só exerciam sua função de capitães e de clérigos respectivamente, mas também, por vezes, negociavam e adquiriam escravos para si. Foi o caso, por exemplo, de um padre capelão que pagou por um direito de uma cabeça de escravatura. ${ }^{39}$

Dentre um universo de nomes predominantemente masculinos envolvidos no comércio de escravos entre Angola e Pernambuco, a presença de um nome feminino nos chamou à atenção. Trata-se de Maria da Silva da Gama, descrita como umas das pessoas a quem os administradores da Companhia de Comércio de Pernambuco passaram letras. No ano de 1763, o nome de Maria da Silva da Gama apareceu ao lado de João de Oliveira Gouvin e outras pessoas envolvidas na saída dos escravos de Luanda, pelos direitos de 350 cabeças que se despacharam, em 23 de julho de 1763, na corveta Nossa Senhora da Guia para Pernambuco. ${ }^{40}$ A presença do nome dessa mulher no Livro da Casa Comercial em Luanda, de certa forma, reforça as notícias sobre participação feminina nos negócios que envolviam o tráfico humano. ${ }^{41}$ 
Todas essas personagens citadas acima, de forma direta ou indireta, estavam envolvidos com o trafico de escravos saídos de Luanda para Pernambuco e outros lugares do Brasil. Igualmente a eles, uma infinidade de outras pessoas também contribuiu para a diáspora de africanos ao longo dos séculos. Os investigadores Débora Albuquerque, Flávio Versiani e José Vergolino, ao se debruçarem no Voyages Database, citaram que entre os séculos XVI e XIX mais de $87 \%$ das viagens que trouxeram escravos da África para Pernambuco partiram originalmente do próprio porto de Pernambuco. Em outras palavras, a maioria das embarcações saía de Pernambuco em direção aos portos da África, e de lá retornava para Pernambuco repleta de escravos. Segundo os referidos investigadores, isso sugere que quem organizava e financiava o desembarque de negros em Pernambuco eram pessoas que ali residiam, principalmente portugueses radicados no Recife. ${ }^{42}$ Nesse sentido, embora não fossem portugueses, nossas personagens citadas acima: o cigano Manuel de Faria Marinho, natural de Pernambuco e feirante nos sertões de Angola; e João de Oliveira Gouvin, Mestre de Campo da praça do Recife e negociante de escravos em Luanda, são exemplos da participação de homens de Pernambuco que faziam parte da estrutura do tráfico de escravos saídos de Angola.

Ainda de acordo com os dados consultados por Albuquerque, Versiane e Vergolino, o porto do Recife, em Pernambuco, foi o terceiro maior porto do Brasil (ficando somente atrás de Rio de Janeiro e Bahia) e o quinto maior porto do mundo a receber escravos da África (sendo o do Rio de Janeiro o primeiro e da Bahia o terceiro do mundo). Em Pernambuco, nos séculos XVII e XVIII, a média era de 2.500 e 3.300 escravos desembarcados por ano. Já na primeira metade do século XIX, essa média saltou para 5.000 desembarcados por ano. ${ }^{43}$

Por nossa vez, também consultamos os dados do Slavevoyages para termos uma ideia da rota e do número de escravos africanos retirados da África Centro-Ocidental, especificadamente entre a segunda metade do século XVIII e a primeira década do século XIX. 
Figura 1: Mapa da rota atlântica de escravos saídos da África Centro-Ocidental para Pernambuco

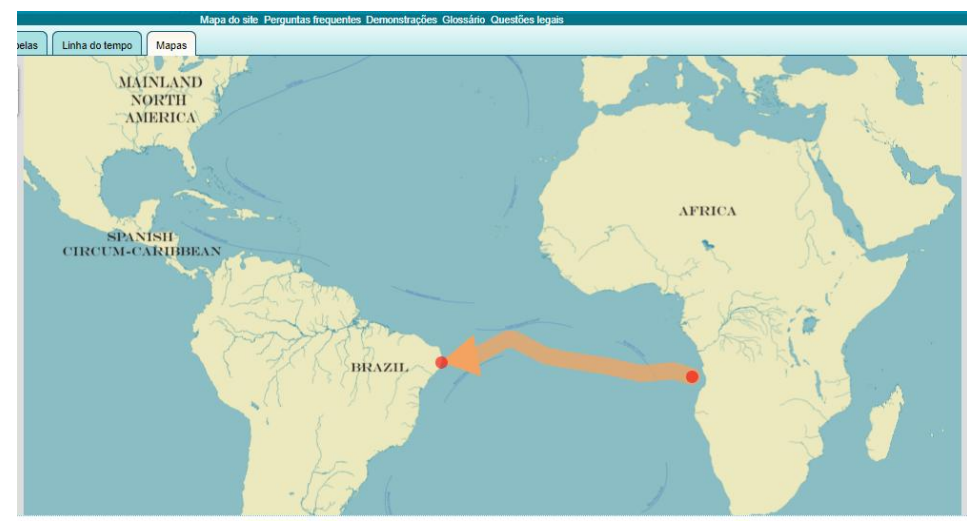

Fonte: http://www.slavevoyages.org/estimates/amfhwcC3. Acesso em: 18 dez. 2018.

Portanto, saiu da África Centro-Ocidental um total estimado de 1.062.164 escravos, cujos destinos eram os diversos portos da América portuguesa: Amazônia, Bahia, Pernambuco, Sudeste do Brasil e demais lugares não especificados. Após a travessia pelo Oceano Atlântico, desembarcaram nesses portos um total aproximado de 964.992 escravos para o dito período. Em relação especificamente a Pernambuco, tem-se um total aproximado de 178.883 escravos embarcados dos portos da África Centro-Ocidental para 164.041 desembarcados nessa capitania da América portuguesa, entre os anos de 1751 e 1810 (Quadro $2) .^{44}$

Quadro 2: Quantidade de escravos embarcados na África Centro-Ocidental e desembarcados em Pernambuco, 1751-1810.

\begin{tabular}{|c|c|c|c|}
\hline Rota & Década & Embarcados & Desembarcados \\
\hline África Centro-Ocidental/Pernambuco & $1751-1760$ & 22.289 & 20.330 \\
África Centro-Ocidental/Pernambuco & $1761-1770$ & 25.947 & 23.942 \\
África Centro-Ocidental/Pernambuco & $1771-1780$ & 18.462 & 16.911 \\
África Centro-Ocidental/Pernambuco & $1781-1790$ & 28.565 & 26.795 \\
África Centro-Ocidental/Pernambuco & $1791-1800$ & 39.185 & 36.714 \\
África Centro-Ocidental/Pernambuco & $1800-1810$ & 44.435 & 39.349 \\
África Centro-Ocidental/Pernambuco & TOTAL & 178.833 & 164.041 \\
\hline
\end{tabular}

Fonte: http://www.slavevoyages.org/estimates/RmfkhfeM. Acesso em: 8 dez. 2018.

Conforme observado, esse número de escravos remetido variava entre as décadas. Contudo, é visível que, a partir de 1780 até 1810, houve um significativo aumento de escravos 
comercializados. Isso poderia estar ligado a diversos fatores de ordem política e econômica a respeito do tráfico. Outra variação que pode ser vista é em relação ao número de escravos embarcados na África Centro-Ocidental (178.833) e o número de escravos desembarcados em Pernambuco (164.041), o que nos dá uma ideia do número de seres humanos que possivelmente morreram ao longo da travessia nessas seis décadas, cujo total foi de 14.842 indivíduos.

A morte de escravos ao longo da travessia chegou a incomodar algumas vezes o governo de Pernambuco, que fazia queixas ao Conselho Ultramarino a respeito dessa situação. No ano de 1761, por exemplo, foi informada pelo governador daquela capitania a falta de cuidados e a desobediência dos contratadores em Angola que, em busca de maior lucro, superlotavam os navios de escravos, ultrapassando os limites estabelecidos. Segundo o governador, a "ganância" e "crueldade" dos contratadores e negociantes particulares de escravos faziam com que adultos e crianças (estas últimas, a depender do tamanho, chamadas de "crias de peito" e "crias de pé") fossem apertados, "sem atenção a área necessária para se deitarem e ar preciso para respirarem". ${ }^{45}$ Até mesmo a água fornecida nas embarcações para os escravos beberem era infecciosa, pois havia o costume de armazená-las dentro de pipas anteriormente usadas para estocar a jeribita e outros licores levados de Pernambuco para Angola, conforme informado no ano de $1762 .^{46}$

Após a travessia do Atlântico, os escravos sobreviventes eram desembarcados nos diversos portos da América portuguesa. Uma parcela desses homens, mulheres e crianças cativos já aportavam doentes. No ano de 1800, a junta governativa da Capitania de Pernambuco enviou ofício ao Conselho Ultramarino, em Lisboa, mostrando-se preocupada com o surto e a proliferação da doença chamada "bexiga" entre os escravos. Somente no referido ano, no Recife, haviam morrido 180 pretos chegados infectados da costa da África. Como forma de conter o contágio, a Junta sugeria deixar os escravos em quarentena antes de colocá-los à venda. De acordo com a Junta, isso facilitaria também para que os lavradores de "fora" tivessem um pouco mais de tempo para chegar à vila do Recife e adquirir esses escravos sobreviventes ainda em primeira mão, sem ter o prejuízo de adquiri-los por segunda ou terceira mão, o que encarecia o produto. ${ }^{47}$

Em relação a Pernambuco, a maior parte da escravatura acabava por ser utilizada nas propriedades agrícolas de plantação de cana e fabrico de açúcar, como também em diversos afazeres nos principais núcleos urbanos da capitania, tanto um quanto outro situado nas áreas litorâneas e entorno. No entanto, a partir do século XVIII, cada vez mais escravos passaram a 
ser conduzidos para o interior em virtude da consolidação do processo de conquista e ocupação do território, que proporcionou um aumento de povoados e vilas, assim como de propriedades rurais. O próprio ofício supracitado, trocado entre a Junta de Pernambuco e o Conselho Ultramarino, em 1800, também traz uma pequena referência sobre a atuação de lavradores que vinham de "fora" em busca de escravos. ${ }^{48}$ Possivelmente o antedito termo estava a se referir a lugares distantes, tanto da costa quanto dos sertões. Nesses casos, para muitos escravos, além da travessia transatlântica, ainda havia uma viagem subsequente em direção ao interior de Pernambuco, que se caracterizaria como uma continuação das rotas dos escravos saídos da África.

Nos sertões de Pernambuco e adjacências, enquanto uns escravos eram introduzidos para realizarem trabalhos rurais, outros eram conduzidos por lá para trabalharem nas minas mais distantes do interior do Brasil. Na busca pelas parcas informações a respeito da entrada de escravos pelo interior de Pernambuco, deparamos com alguns vestígios acerca disso. A entrada dos escravos que seguiam por terra de Pernambuco até as "minas de ouro" já ocorria, pelo menos, desde antes de 1725. No referido ano, o provedor da Fazenda Real da Capitania de Pernambuco e a Coroa Portuguesa debatiam sobre a conveniência de administrar o contrato dos escravos que partiam da referida capitania "por terra e por mar" em direção às tais minas. ${ }^{49}$ Ora, supomos que o caminho por terra se referia ao trajeto que adentrava o interior da Capitania de Pernambuco, margeando a Bahia, até chegar à região das Minas Gerais. Já o caminho por mar, se referia à cabotagem a partir do porto do Recife em direção sul até chegar a outros portos como o da Bahia ou Rio de Janeiro, por onde, a partir de lá, os escravos entravam também em direção às Minas. ${ }^{50}$

Mais informações sobre a saída de escravos "de Pernambuco para todas as Minas" podem ser vistas num contrato dos direitos pagos sobre os tais escravos, em 1757, localizado no Livro de Registro das Condições dos Contratos Reais da Repartição da África Ocidental, Maranhão e Baía, 1753 a $1804 .{ }^{51}$ Uma das cláusulas das condições desse contrato versa sobre as punições que seriam tomadas sobre fraudes e descaminhos feitos por transgressores. Segundo consta no documento: "muitas pessoas" interrompiam sua viagem precocemente ao descaminhar e vender esses escravos para outros indivíduos, sendo então esses cativos aplicados em "diferentes usos", e não nos trabalhos das minas. Para melhor controlar essa burla, foi instituído que "todas as pessoas que levassem escravos para as Minas com guias pelos ditos portos (Pernambuco, Bahia e Rio de Janeiro) seriam obrigadas as apresentá-las [as ditas guias] em termo de quinze dias depois de sua chegada ao Provedor da Fazenda". 52 
Outra cláusula do supracitado documento dá a entender que os direitos sobre os escravos deveriam ser pagos em relação àqueles que seriam conduzidos para algumas das minas, e o pagamento não seria feito sobre escravos que não fossem para lá. Por isso, podemos inferir que, em meados do século XVIII, em Pernambuco, havia dois grupos de escravos que adentravam os sertões: aqueles disponíveis para as minas; e aqueles escravos disponíveis para outros usos (que não as minas propriamente ditas), onde deveriam exercer as mais diversas atividades: agricultura, criação de gado, entre outras. Talvez seja por isso que (no intuito de diferenciar esses dois grupos de escravos) conste na dita cláusula o seguinte: "[...] e para se evitarem os enganos que se poderão fazer serão obrigados todos os escravos que entrarem nos distritos das ditas Minas a mostrarem nos registros delas, aonde se pagam os direitos da entrada guia dele [escravo]."

No supracitado contrato, consta que as mesmas cláusulas deveriam ser aplicadas também para a Bahia e Rio de Janeiro. Deve ser por isso que, em relação a Bahia, Beatriz Azevedo, ao analisar os contratos de escravos da primeira metade do século XVIII, constatou o seguinte: que nenhum escravo fosse levado às Minas "sem as guias, a exceção dos escravos levados para o serviço junto a fazendeiros e roceiros do caminho para as minas. No entanto, se por acaso estes últimos depois fossem mais tarde levados para as áreas mineradoras, há o alerta para que o mesmo imposto fosse pago, com pena de perda de escravo". 54 Ora, isso que ocorria em relação à Bahia era algo semelhante ao que ocorria em Pernambuco, conforme vimos mais acima.

Por fim, em outro documento, deparamos com mais vestígios a respeito da entrada de escravos pelo interior de Pernambuco e dos caminhos percorridos por essas pessoas. Em correspondência trocada entre o governador de Pernambuco e o Conselho Ultramarino a respeito de "negros escravos" que iriam trabalhar na Mina dos Kariris Novos (então localizada numa área entre Pernambuco, Ceará e Paraíba), ${ }^{55}$ no ano de 1757 , constam informes de controle para que não houvesse saída de escravos da agricultura da própria capitania para a referida mina.

E para que os mais ramos da mesma [agricultura] não padecessem, quando as minas florescessem, publiquei logo bandos por todo o destrito deste governo como consta da cópia N. 3 em que proíbe que pessoa alguma podesse hir para ellas sem passaporte mas obrigando as que quando pretendessem mostrassem o exercício e ocupaçoens que se empregavão para deste modo a não permitir aquelles que sendo ocupados na mesma agricultura a pretendessem desamparar para seguir este caminho em seu prejuízo a que me sugerio ainda da referida Companhia que toda a compor de escravos novos que ao não ficarem nesta capitania pelo princípio referido seguirão o caminho das minas gerais pello [ilegível] para onde forão as mais que 
com elles vierão dos portos da África, em que forão resgatados por ser a sahida que lle costumão dar os negociantes desta praça e da Bahia. ${ }^{56}$

Embora o trecho do documento seja confuso, dá-se a entender que o governador de Pernambuco usaria os escravos novos chegados dos portos da África que saíam para as Minas Gerais (conforme negócios já existentes em Pernambuco e Bahia com as Minas Gerais). Em outras palavras, haveria o cuidado de não fazer uso de escravos que já estavam inseridos na agricultura de Pernambuco, mas sim de utilizar alguns que acabavam de chegar da África. Para controlar a entrada de pessoas em direção às minas, o governador informou que faria uso de passaportes onde constasse declarado o exercício e a ocupação dos indivíduos. ${ }^{57}$ Portanto, o documento dá a entender que escravos estariam incluídos nesse uso de passaporte. Isso não é de se estranhar, pois a utilização de passaportes por parte de escravos que entravam no sertão do Brasil era prática adotada também na Bahia. ${ }^{58}$

As rotas pelo interior de Pernambuco eram longas, difíceis e perigosas. Os sujeitos responsáveis pelo cumprimento do contrato de escravos estariam expostos aos mais diversos perigos, dentre eles, os descaminhos, os assaltos praticados por terceiros ou, até mesmo, revolta e fuga por parte dos cativos. Em outras palavras, os escravos poderiam se utilizar dos lugares ermos para se amotinarem. Em 1749, numa carta expedida pela Câmara de Goiana (em Pernambuco) ao rei, por exemplo, falou-se, dentre outras coisas, a respeito de um comboio cujo condutor e alguns escravos haviam assassinado seu senhor. ${ }^{59}$ Provavelmente, por esse e outros casos de resistência escrava contra a subjugação que passavam, havia uma cláusula no contrato de 1757 que fala da permissão para que os oficiais que andassem nas diligências do contrato trouxessem armas de fogo. ${ }^{60}$ Além disso, as distâncias e a geografia dos sertões também eram motivos de queixas. No já mencionado ofício que trata sobre a ida de escravos para trabalharem nas minas dos Kariris Novos, comentou-se sobre a distância entre a costa marítima e a mina do dito sertão, do tempo de travessia, das dificuldades dos caminhos e da necessidade de terem auxílio das pessoas naturais da terra (indígenas), conforme pode ser visto abaixo:

É sem dúvida que estas minas [dos Kariris Novos] distam deste porto [do Recife] quinze dias de viagem e segundo o caminho, que se faz em cada um neste continente; me persuado ser verdadeira a conta que fazem de cento e cinquenta léguas e o conhecimento que dele me deu outra [ilegível] e tantas que fiz de giro na visita geral, me obriga a dizer a Vossa Excelência que para a defesa dele se não necessitar mais que ter as praças e partir bem prevenidos que no interior em passando dez ou doze léguas da marinha só com consentimento dos naturais; pois sem este a quantidade de desfiladeiros, gargantas, bosques e gerais unida da falta de água que nas travessias se encontra, a fazem impenetrável. ${ }^{61}$ 
Nesse sentido, de grandes distâncias, de quantidade de desfiladeiros, gargantas, bosques e pelo problema de falta de água, o interior de Pernambuco e das capitanias vizinhas mostrava-se, ao menos na percepção das autoridades da colônia, como um lugar de difícil penetração para os negociantes de escravos. Contudo, podemos associar que a travessia não deveria ter sido fácil também para os escravos africanos recém-chegados a esses sertões, seja aqueles de passagem para a região das Minas Gerais, seja aqueles que ficaram na mina dos Kariris Novos ou nas diversas propriedades rurais de criação de gado, de plantação de algodão, de roça de mandioca e feijão espalhados pelo interior de Pernambuco. Porém, é bem verdade que, com o passar do tempo, esses africanos e seus descendentes acabavam por adquirir afinidade com esses sertões. Alguns escravos chegaram a constituir família, outros se tornaram legalmente livres, já outros empreenderam fugas em busca da sua liberdade. Fugidas para os "matos", essas pessoas passavam a fazer uso deles para se esconder e sobreviver.

Vale salientar que parte dos cativos remetidos para o Brasil havia nascido e/ou vivido determinado tempo em locais de Angola cuja miscigenação das culturas entre portugueses, mbundos e ovimbundos já estava bastante consolidada há séculos. Eram escravos que viviam nos núcleos coloniais e, por negócios de seus senhores, acabaram sendo vendidos para o tráfico atlântico. Estamos a falar não só de Luanda e Benguela, ambas situadas no litoral, mas também de enclaves no interior do continente, estabelecidos pelos portugueses desde fins do século XVI e início do XVII, como Muxima, Massangano, Cambambe, Ambaca, Caconda entre outros. Isso para não falar também daqueles indivíduos que eram reconhecidos como livres, e, por uma série de fatores, foram reduzidos ilegalmente à condição de cativos, sendo enviados ou não para a América. Todos estes deveriam falar tanto o português quanto o kimbundo e outros idiomas bantos. Ao embarcarem nos navios negreiros, esses indivíduos acima citados, provenientes de Luanda, Benguela e sertões de domínio português, dividiam espaço com outros escravos procedentes de outras distantes regiões, da África profunda, das quais os portugueses não dominavam, mas tinham acesso a eles por meio de uma complexa rede escravista africana. Sendo consideradas "mercadorias vivas", todos esses homens e mulheres, adultos e crianças percorriam milhares de quilômetros por terra e mar nas piores condições existentes. 


\section{Notas}

${ }^{1}$ Recentemente, em artigo, Alexandre Vieira realizou uma discussão historiográfica por meio das ideias desenvolvidas de diversos investigadores de diferentes nacionalidades que tratam da origem dos escravos e do tráfico atlântico entre Brasil e Angola. Dentre eles, Philip Curtin, Paul Lovejoy, Ralph Delgado, David Birmingham, Joseph Miller, Roquinaldo Ferreira, Mariana Cândido, entre outros. Sobre essa discussão, ver: RIBEIRO, Alexandre Vieira. Apontamentos sobre o tráfico de escravos entre Angola e Brasil. In: PAIVA, Eduardo França; SANTOS, Vanicléia Silva (Org.). África e Brasil no mundo moderno. São Paulo: Annablume; Belo Horizonte: Programa de Pós-Graduação em História, UFMG, 2013. p. 29-48. Por sua vez, Leila Leite Hernandez realizou uma enriquecedora revisão historiográfica do tráfico de escravos e as dinâmicas sociais e culturais com base nas obras dos principais estudiosos de Estudos Africanos, oferecendo uma síntese do processo de constituição da História da África no Brasil. HERNANDEZ, Leila Leite. História da África no Brasil. Revista Cerrados (UnB. Impresso), v. 19, p. 231-242, 2010.

${ }^{2}$ Recentemente, Suely de Almeida afirmou que a historiografia que trata da escravidão em Pernambuco ainda é tímida, não avançando muito no tema a respeito do século XVIII, embora hoje já se saiba que o porto de Pernambuco figure no quarto lugar dentre aqueles que na América mais receberam cativos. ALMEIDA, Suely Cordeiro de. Rotas atlânticas: o comércio de escravos entre Pernambuco e Costa da Mina, c. 1724-c.1752. História, São Paulo, v. 37, 2018. Disponível em: http://www.scielo.br/pdf/his/v37/1980-4369-his-37e2018022.pdf. Acesso em: 17 nov. 2018.

${ }^{3}$ BLUTEAU, Raphael. Vocabulario portuguez \& latino: aulico, anatomico, architectonico... Coimbra: Collegio das Artes da Companhia de Jesus, 1712-1728. v. 7, p. 613.

${ }^{4}$ SILVA, Antonio de Moraes. Diccionario da lingua portugueza: recompilado dos vocabularios impressos ate agora, e nesta segunda edição novamente emendado e muito acrescentado. Lisboa: Typographia Lacerdina, 1813 , p. 693.

${ }^{5}$ Nas últimas décadas, a origem da palavra sertão, bem como seus variados sentidos, rendem imbricadas discussões na Academia.

${ }^{6}$ CORRÊA, Elias Alexandre da Silva. História de Angola. Lisboa: Editorial Ática, 1937. Colecção dos Clássicos da Expansão Portuguesa. Série E, Império Africano). p. 27.

${ }^{7}$ A mandioca e o milho, originários na América, haviam sido introduzidos pelos portugueses na África desde o século XVI, onde passaram a ser cultivados.

8 ALENCASTRO, Luiz Felipe de. África, números do tráfico atlântico. In: SCHWARCZ, Lilia Moritz; GOMES, Flávio (Org.). Dicionário da escravidão e liberdade: 50 textos críticos. São Paulo: Companhia das Letras, 2018. pp. 57-63.

9 ALMEIDA, Suely Cordeiro de; SOUZA, Jéssica Rocha de. O comércio de almas: as rotas entre Pernambuco e a costa da África, 1774-1787. Revista Ultramares Dossiê, n. 3, jan./jul., 2013. p. 39 Ainda segundo Almeida, com o advento da Companhia Geral de Pernambuco, e maior dedicação dada ao comércio de escravos com a África Centro-Ocidental, "o comércio com a Costa da Mina não foi de todo cessado apesar da fraca representatividade que essa rota irá assumindo paulatinamente durante a vigência da Companhia". ALMEIDA; SOUZA, 2013, p. 45.

${ }^{10}$ FERREIRA, Roquinaldo. África durante o comércio negreiro. In: SCHWARCZ, Lilia Moritz; GOMES, Flávio (Org.). Dicionário da escravidão e liberdade: 50 textos críticos. São Paulo: Companhia das Letras, 2018. p. 56.

${ }^{11}$ ALENCASTRO, 2018, p. 57-63.

${ }^{12}$ Em relação a detalhes mais específicos da organização do tráfico entre Angola e Brasil e a atuação da Coroa e dos particulares, ver PIMENTEL, Maria do Rosário. Viagem ao fundo das consciências: a escravatura na Época Moderna. Lisboa: Edições Colibri, 1995. p. 83-95. ALMEIDA; SOUZA, 2013, p. 39.

${ }^{13}$ De acordo com Joaquim Veríssimo Serrão, a dita Companhia era formada pelo cabedal dos interessados e sem participação da Fazenda Real. Ela "podia fabricar naus mercantis e de guerra nos estaleiros do Reino; cortar madeiras no distrito do Porto, em Alcácer do sal e noutras matas que não estivessem cortadas; levantar gente de mar e guerra para as guarnições a manter no Reino, nas Ilhas e nas capitais de Pernambuco e da Paraíba. Os seus navios só podiam ser recrutados para o serviço régio em caso de perigo na costa, barras e portos do Reino. A companhia dispunha ainda de casas e armazéns para o seu despacho e arrecadação das fazendas". SERRÃO, Joaquim Veríssimo. História de Portugal: o despotismo iluminado, 1750-1807. 6. ed. Lisboa: Editorial Verbo, 2004. p. 178-179. Em estudo recente, Erika Dias aborda a instalação da Companhia Geral de Comercio na capitania de Pernambuco. De acordo com ela, havia uma disposição real em criar uma Companhia de Comércio com a participação de negociantes e quaisquer outras pessoas de Pernambuco para serem acionistas dela. Porém, muitos pernambucanos ficaram reticentes com a criação da dita Companhia. DIAS, Erika. A capitania de Pernambuco e a instalação da Companhia Geral de Comércio. In: ACTAS do Congresso Internacional Espaço 
Atlântico de Antigo Regime: poderes e sociedades. Lisboa: Centro de História da Além-Mar Faculdade de Ciências Sociais e Humanas, Universidade Nova de Lisboa \& Departamento de Ciências Humanas Instituto de Investigação Científica Tropical, 2005.

${ }^{14}$ Em relação a detalhes mais específicos da organização do tráfico entre Angola e Brasil e a atuação da Coroa e dos particulares, ver PIMENTEL, 1995, p. 83-95. ALMEIDA; SOUZA, 2013, p. 39.

15 COLLECÇ̃̃O da Legislação Portugueza: desde a ultima compilação das ordenações. Redegida pelo desembargador Antonio Delgado da Silva. Legislação de 1775 a 1790. Lisboa: Typografia Maigrense, 1828 a. v. 3. p. 535.

${ }^{16}$ Sobre as rotas do litoral e sertão da África Centro-Ocidental, ver SANTOS, Maria Emília Madeira. Viagens e apontamentos de um portuense em África: diário de Antônio Ferreira da Silva Porto. Coimbra: Biblioteca Geral da Universidade de Coimbra, 1986. SANTOS, Maria Emília Madeira. Viagens de exploração terrestre dos portugueses em África. Lisboa: Centro de Estudos de História e Cartografia Antiga, Instituto de Investigação Científica Tropical, 1978. PIMENTEL, Maria do Rosário. Portugal e o tráfico de escravos: do 'filhamento’ ao comércio organizado. In: ASSIS, Angelo Adriano Faria de; LEVI, Joseph Abraham; MANSO, Maria de Deus Beites. A expansão: quando o mundo foi português: da conquista de Ceuta, 1415, à atribuição da soberania de Timor-Leste, 2002. Braga: NICPRI, 2014. p. 254-289.

17 AHU-Angola, cx. 100, doc. 36.

${ }^{18}$ FERREIRA, 2018, p. 55.

19 PIMENTEL, 1995.

${ }^{20}$ BNP. RES. 1698//4 v. Bosquejo sobre o comércio em escravos, reflexões sobre este tráfico considerado moral, política e christamente. Londres: Impresso por Ellerton e Henderson, 1821. p. 33-34.

${ }^{21}$ BNP. RES. 1698//4 v. Ibid., 1821, p. 34-36.

${ }^{22}$ Tudo isso pode ser percebido nas diversas correspondências trocadas entre os poderes locais das colônias e a Metrópole portuguesa. Ver, por exemplo, os seguintes documentos: Manifesto de Dom João Manoel de Noronha, Governador e Capitão geral do reino de Angola, da forma com que governou aquelle Reino, e do que se sucedeu no tempo do seu governo. BPE - Cod. CXVI/2-15, n. ${ }^{\circ}$ 11, p. 26; Já no Arquivo Histórico Ultramarino, encontra-se o seguinte doc: AHU-ACL-CU-015, cx. 87, D. 7129. Conferir também os relatos do cronista militar Elias Alexandre Corrêa, 1937.

${ }^{23}$ AHU-Angola, cx. 65, doc. 14.

${ }^{24}$ AHU-Angola, cx. 100, doc. 36.

${ }^{25}$ Consta nesse documento, elaborado pelo escrivão da Ouvidoria Geral do Reino de Angola, no ano de 1800 , que Manoel de Faria Marinho assinou um termo, no ano de 1798, comprometendo-se a "sair deste Reino [Angola] e não voltar mais aos sertões dele”. Antes, o dito Manoel já havia sido advertido para não deixar os limites da cidade de Luanda em direção aos sertões do dito reino e de Benguela. Ao que parece, o caso ocorreu por uma contenda entre o dito cigano e um capitão-mor, que envolveu o poder local e o poder da Coroa em Angola. AHU-Angola, cx. 97, doc. 49; AHU-Angola, cx. 97, doc. 52. AHU-Angola, cx. 97, doc. 57.

26 "Ciganos" [calons] degredados da Metrópole portuguesa para o Brasil, por vezes, acabavam sendo depois expulsos pelos governadores das capitanias daquela colônia em direção à África. Foi o caso, por exemplo, de ciganos que foram exterminados (expulsos) de Pernambuco e do Rio de Janeiro para Angola. Ver COSTA, Elisa Maria Lopes da. Contributos ciganos para o povoamento do Brasil, séculos XVI-XIX. Revista Arquipélago, História, 2. ${ }^{\text {a }}$ série, v. 9, p. 153-182, 2005.

${ }^{27}$ AHU-Angola, cx. 97, doc. 49; AHu-Angola, cx. 97, doc. 52. AHU-Angola, cx. 97, doc. 57.

${ }^{28} \mathrm{O}$ fato de Manuel também se referir a "dinheiro" portado por ciganos nos caminhos dos sertões indica que esses ciganos não só faziam trocas diretas de mercadorias, como também podiam negociar com moedamercadoria e, até mesmo, com moedas cunhadas. Ver: AHU-Angola, cx. 97, doc. 49; AHu-Angola, cx. 97, doc. 52. AHU-Angola, cx. 97, doc. 57. Nas sociedades em Angola, as moedas-mercadorias poderiam ser conchas (zimbos) e outros produtos que tinham padrão de valor e serviam como intermediário nas trocas. Com a chegada dos europeus àquele território, havia também a presença de moedas cunhadas, como as feitas de cobre. Nesse sentido, o fato de Manoel fazer referência a "dinheiro" poderia significar tanto moedas-mercadorias quanto moedas cunhadas. Segundo o Museu da Casa da Moeda de Portugal, ao longo da história da Humanidade, as trocas diretas, realizadas por diferentes grupos humanos, consistiam na troca de uma mercadoria por outra. Já o uso da moeda-mercadoria, era quando os grupos faziam uso de determinado produto como padrão de valor e intermediário nas trocas. Na Antiguidade, o sal, por exemplo, foi uma das mercadorias que primeiro foram usadas como padrão e intermediário das trocas, seguido depois de conchas e metais (o cobre, a prata e o ouro). Por fim, a moeda cunhada, isto é, com peso, forma e impressões padronizadas, também passaram a ser usadas no comércio. Entretanto, salientamos que, ao longo dos milênios, o surgimento de um novo modelo não necessariamente decretou o fim do modelo anterior. Nesse caso, as três formas chegaram a coexistir e, até 
mesmo, a serem usadas simultaneamente em diferentes ocasiões. MUSEU DA CASA DA MOEDA DE PORTUGAL. Exposição: Da Ausência de Moeda à Moeda Virtual. Local: Centro Comercial Colombo, 2017.

${ }^{29}$ AHU-Angola, cx. 97, doc. 49; AHu-Angola, cx. 97, doc. 52. AHU-Angola, cx. 97, doc. 57;

${ }^{30}$ AHU-Angola, cx. 97, doc. 49; AHU-Angola, cx. 97, doc. 52. AHU-Angola, cx. 97, doc. 57.

${ }^{31}$ Inclusive, até meados do século XIX, há registro da ida de colonos do Brasil para Angola. Foi o caso de um grupo de brasileiros que fundou uma colônia em Mossamedes. Biblioteca da Ajuda. Ms. Av. 54-XI-2, n. ${ }^{\circ}$ 53-53a. ${ }_{32}$ AHU-Angola, cx. 75, doc. 79.

${ }^{33}$ AHU-Angola, cx. 84, doc. 14-A.

${ }^{34}$ Ver: AHU-Angola, cx. 28, doc. 37.

${ }^{35}$ George Cabral de Souza, em sua investigação sobre o grupo mercantil do Recife colonial (c. 1654-c. 1759), identificou um João de Oliveira Gouvin I, nascido no ano de 1683, em São Pedro Gondarém, termo de Vila Nova de Cerveira, e falecido no ano de 1760. Casado com Helena Bernarda, o dito Gouvin I deixou três descendentes, dentre eles, um João de Oliveira Gouvin II. Este último pode ser o nosso personagem, mestre de campo da Praça do Recife, envolvido no tráfico de escravos de Angola para Pernambuco. Segundo Souza, o Gouvin I era mercador e fora para o Recife em 1715, onde se atrelou ao negócio negreiro com a África. Sendo assim, ao que parece, João de Oliveira II seguiu os passos do pai no que concerne ao negócio negreiro entre o Recife e África. SOUZA, George F. Cabral de. Tratos e mofatras: o grupo mercantil do Recife colonial, c. 1654c.1759. Recife: Ed. Universitária da UFPE, 2012. p. 456.

${ }^{36}$ AHU_ACL_CU_015, cx. 104, D. 8074.

${ }^{37}$ Trata -se de um livro de contratos comerciais em Luanda (África). Destacam-se os contratos de escravos e marfim. ANTT. Feitos Findos, Livros dos Feitos Findos, liv. 62; ANTT. Feitos Findos, Livros dos Feitos Findos, liv. 63. PT-TT-LFF-0063_m0023.TIF.

${ }^{38}$ Consta no Livro da Casa Comercial de Luanda que, em 5 de março do ano de 1766, João de Oliveira Gouvin realizou um saque a ordem do Provedor João do Rego Barros, cuja quantia foi lançada em conta de uma terceira pessoa, o Doutor Manoel Pinto da Cunha e Souza. ANTT. Feitos Findos, Livros dos Feitos Findos, liv. 62. ANTT PT-TT-LFF-0062 m0152.TIF. Por sua vez, no acervo do AHU, identificamos que, em Pernambuco, ao longo do período colonial, diversos indivíduos da família Rego Barros foram batizados com o nome de João. Cada um deles ocupou diferentes ou iguais tipos de cargos nos sucessivos séculos. Exemplos: Em 1654, um João do Rego Barros aparece como capitão. Em 1725, aparece um padre João de Barros envolvido em negócios de tabaco (ver AHU_ACL_CU_015, cx. 32, D. 2953). Já entre 1673 até, pelo menos, 1770, sempre existiu um João do Rego Barros como detentor do cargo de Provedor da Fazenda Pernambuco, ou seja, ao longo de um século, o mesmo cargo ficou com a mesma família, e alguns dos detentores tinham o nome de João. No ano de 1725, um João do Rego Barros, provedor da Fazenda Real de Pernambuco, envia uma carta ao rei de Portugal [D. João V], sobre a conveniência de administrar o contrato dos escravos que vão por terra e por mar para as minas de ouro da mesma forma que o da dízima da Alfândega (ver AHU_ACL_CU_015, cx. 31, D. 2845).

${ }_{39}$ ANTT. Feitos Findos, Livros dos Feitos Findos, liv. 62. PT/TT/LFF/0062.

${ }^{40}$ ANTT. Feitos Findos, Livros dos Feitos Findos, liv. 62. PT/TT/LFF/0062.

${ }^{41}$ A participação de mulheres à frente de negócios na África não era algo estranho. Segundo Philip Havik, na África Ocidental, entre os séculos XVI até fim do século XIX, era comum mulheres, muitas delas viúvas, batizadas com nomes portugueses, gerir negócios de sua casa. Esse protagonismo da mulher nos negócios atlânticos estava ligado a alguns fatores em conjunto: o caráter matrilinear das sociedades africanas (que tanto surpreendeu e preocupou o europeu), o fato de os europeus serem geralmente alheios ao meio e às redes de parentesco que garantiam a algumas mulheres a posição de força. Sendo assim, baseado em Havik, podemos dizer que há possibilidade da personagem que apareceu envolvida na saída de escravos, ao lado do pernambucano João de Oliveira Gouvin, ser uma dessas mulheres que geriam negócios na África. HAVIK, Philip J. Matronas e mandonas: parentesco e poder feminino nos rios de Guiné, século XVIII. In: PANTOJA, Selma (Org.). Entre Áfricas e Brasis. Brasília: Paralelo 15; São Paulo: Marco Zero, 2001. p. 13-34.

${ }_{42}$ ALBUQUERQUE, Débora de Souza Leão; VERSIANI, Flávio Rabelo; VERGOLINO, José Raimundo Oliveira. Financiamento e organização do tráfico de escravos para Pernambuco no século XIX. Revista Economia, Brasília, v. 14, n. 1A, p. 211-225, jan./abr. 2013. p. 213-214.

${ }^{43}$ Ibid.

${ }^{44}$ The Trans-Atlantic Slave Trade Database. Disponível em: http://www.slavevoyages.org/estimates/ RmfkhfeM. Acesso em: 15 jan. 2019.

${ }^{45}$ AHU_ACL_CU_015, cx. 94. D. 7456.

${ }^{46}$ AHU_ACL_CU_015, cx. 98. D. 7661.

${ }^{47}$ AHU_ACL_CU_015, cx. 222, D. 15004.

${ }^{48}$ Ibid.

${ }^{49}$ AHU_ACL_CU_015, cx. 31, D. 2845. 
${ }^{50}$ Os escravos não adentravam somente por Pernambuco. No que concerne aos escravos que entravam pela Bahia em direção as Minas, na primeira metade do século XVIII, ver AZEVEDO, Beatriz Líbano Bastos. $O$ negócio dos contratos: contratadores de escravos na primeira metade do século XVIII. Dissertação (Mestrado) Programa de Pós-Graduação em História Econômica, Faculdade de Filosofia, Letras e Ciências Humanas, Universidade de São Paulo, São Paulo, 2013. p. 116-117.

51 AHTC. 4253. (1753-1808) - Livro de Registro das Condições dos Contratos Reais da Repartição da África Ocidental, Maranhão e Baía, 1753 a 1804. "Contrato dos Direitos que Pagam os escravos que saem de Pernambuco para todas as Minas, rematado a Francisco da Silva Pereira por três anos que tiveram princípio em o primeiro de julho de 1757, cada um deles em preço de um conto de reis livres para a Fazenda Real." fl 17-20.

52 AHTC. 4253 (1753-1808) - Livro de Registro das Condições dos Contratos Reais da Repartição da África Ocidental, Maranhão e Baía, 1753 a 1804. fl. 18.

53 AHTC. 4253 (1753-1808) - Livro de Registro das Condições dos Contratos Reais da Repartição da África Ocidental, Maranhão e Baía, 1753 a 1804. fl. 19.

${ }_{54}^{5}$ AZEVEDO, 2013, p. 117.

${ }^{55}$ As minas dos Kariris Novos tinha essa denominação por estar incrustada numa região ocupada pela população autóctone Kariris. Sobre esse grupo indígena e sobre o processo de ocupação desses sertões por parte dos colonizadores, ver trabalho de OLIVEIRA, Antonio José. Os Kariri: resistências à ocupação dos sertões dos Cariris Novos no século XVIII. Tese (Doutorado) - Programa de Pós-Graduação em História, a Universidade Federal do Ceará, Fortaleza, 2017.

${ }^{56}$ AHU_ACL_CU_015, cx. 82, D. 6880.

${ }^{57}$ AHU_ACL_CU_015, cx. 82, D. 6880.

58 Ao analisar a entrada de escravos no sertão da Bahia, Iasmim Cezar afirma que a Coroa regulava a atividade de redistribuição de escravos desenvolvida entre os pequenos comerciantes e os grandes importadores de Salvador. Desse modo, era exigida aos negociantes uma documentação específica expedida na Bahia, no intuito de fiscalizar os envios de escravos. Essa documentação, as guias de passaporte, registrava a saída de escravos do porto baiano para o interior. Ao analisar algumas dessas guias, Iasmim Cezar, levantou diversos dados: quantidade de escravos que entraram nos sertões da Bahia entre os anos de 1778, ocupação desses escravos (agricultura, pecuária), destino final entre outras coisas. CEZAR, Iasmim de Oliveira. A caminho dos sertões: o tráfico interno movimentando o interior baiano, 1778-1798. 2016. Trabalho de Conclusão de Curso (Licenciatura em História) - Departamento de Ciências Humanas, Universidade do Estado da Bahia, Campus-Jacobina, Jacobina, 2016. p. 30.

${ }^{59}$ Infelizmente não temos mais detalhes sobre o referido caso ocorrido em Goiana, pois o documento que trata acerca dele tem partes ilegíveis. Sendo assim, baseamo-nos no fato descrito no catálogo do acervo de manuscritos avulsos de Pernambuco. AHU_ACL_CU_015, Cx.69, D.5806.

${ }^{60}$ AHTC. 4253. (1753-1808) - Livro de Registro das Condições dos Contratos Reais da Repartição da África Ocidental, Maranhão e Baía, 1753 a 1804. fl. 19.

${ }^{61}$ AHU_ACL_CU_015, cx. 82, D. 6880.

\section{Referências Bibliográficas}

ALBUQUERQUE, Débora de Souza Leão; VERSIANI, Flávio Rabelo; VERGOLINO, José Raimundo Oliveira. Financiamento e organização do tráfico de escravos para Pernambuco no século XIX. Revista Economia, Brasília, v. 14, n. 1A, p. 211-225, jan./abr. 2013.

ALENCASTRO, Luiz Felipe de. África, números do tráfico atlântico. In: SCHWARCZ, Lilia Moritz; GOMES, Flávio (Org.). Dicionário da escravidão e liberdade: 50 textos críticos. São Paulo: Companhia das Letras, 2018.

ALMEIDA, Suely Cordeiro de; SOUZA, Jéssica Rocha de. O comércio de almas: as rotas entre Pernambuco e a costa da África, 1774-1787. Revista Ultramares Dossiê, n. 3, jan./jul., 2013. 
ALMEIDA, Suely Cordeiro de. Rotas atlânticas: o comércio de escravos entre Pernambuco e Costa da Mina, c. 1724-c.1752. História, São Paulo, v. 37, 2018. Disponível em: http://www.scielo.br/pdf/his/v37/1980-4369-his-37-e2018022.pdf. Acesso em: 17 nov. 2018.

AZEVEDO, Beatriz Líbano Bastos. O negócio dos contratos: contratadores de escravos na primeira metade do século XVIII. Dissertação (Mestrado) - Programa de Pós-Graduação em História Econômica, Faculdade de Filosofia, Letras e Ciências Humanas, Universidade de São Paulo, São Paulo, 2013.

BLUTEAU, Raphael. Vocabulario portuguez \& latino: aulico, anatomico, architectonico... Coimbra: Collegio das Artes da Companhia de Jesus, 1712-1728. 8 v.

CEZAR, Iasmim de Oliveira. A caminho dos sertões: o tráfico interno movimentando o interior baiano, 1778-1798. 2016. Trabalho de Conclusão de Curso (Licenciatura em História) - Departamento de Ciências Humanas, Universidade do Estado da Bahia, Campus-Jacobina, Jacobina, 2016.

CORRÊA, Elias Alexandre da Silva. História de Angola. Lisboa: Editorial Ática, 1937. Colecção dos Clássicos da Expansão Portuguesa. Série E, Império Africano).

DIAS, Erika. A capitania de Pernambuco e a instalação da Companhia Geral de Comércio. In: ACTAS do Congresso Internacional Espaço Atlântico de Antigo Regime: poderes e sociedades. Lisboa: Centro de História da Além-Mar Faculdade de Ciências Sociais e Humanas, Universidade Nova de Lisboa \& Departamento de Ciências Humanas Instituto de Investigação Científica Tropical, 2005.

FERREIRA, Roquinaldo. África durante o comércio negreiro. In: SCHWARCZ, Lilia Moritz; GOMES, Flávio (Org.). Dicionário da escravidão e liberdade: 50 textos críticos. São Paulo: Companhia das Letras, 2018.

HAVIK, Philip J. Matronas e mandonas: parentesco e poder feminino nos rios de Guiné, século XVIII. In: PANTOJA, Selma (Org.). Entre Áfricas e Brasis. Brasília: Paralelo 15; São Paulo: Marco Zero, 2001

HERNANDEZ, Leila Leite. História da África no Brasil. Revista Cerrados (UnB. Impresso), v. 19, p. 231-242, 2010.

OLIVEIRA, Antonio José. Os Kariri: resistências à ocupação dos sertões dos Cariris Novos no século XVIII. Tese (Doutorado) - Programa de Pós-Graduação em História, a Universidade Federal do Ceará, Fortaleza, 2017.

PIMENTEL, Maria do Rosário. Viagem ao fundo das consciências: a escravatura na Época Moderna. Lisboa: Edições Colibri, 1995.

PIMENTEL, Maria do Rosário. Portugal e o tráfico de escravos: do 'filhamento' ao comércio organizado. In: ASSIS, Angelo Adriano Faria de; LEVI, Joseph Abraham; MANSO, Maria de Deus Beites. A expansão: quando o mundo foi português: da conquista de Ceuta, 1415, à atribuição da soberania de Timor-Leste, 2002. Braga: NICPRI, 2014. 
RIBEIRO, Alexandre Vieira. Apontamentos sobre o tráfico de escravos entre Angola e Brasil. In: PAIVA, Eduardo França; SANTOS, Vanicléia Silva (Org.). África e Brasil no mundo moderno. São Paulo: Annablume; Belo Horizonte: Programa de Pós-Graduação em História, UFMG, 2013.

SANTOS, Maria Emília Madeira. Viagens e apontamentos de um portuense em África: diário de Antônio Ferreira da Silva Porto. Coimbra: Biblioteca Geral da Universidade de Coimbra, 1986.

SANTOS, Maria Emília Madeira. Viagens de exploração terrestre dos portugueses em África. Lisboa: Centro de Estudos de História e Cartografia Antiga, Instituto de Investigação Científica Tropical, 1978.

SERRÃO, Joaquim Veríssimo. História de Portugal: o despotismo iluminado, 1750-1807. 6. ed. Lisboa: Editorial Verbo, 2004.

SILVA, Antonio de Moraes. Diccionario da lingua portugueza: recompilado dos vocabularios impressos ate agora, e nesta segunda edição novamente emendado e muito acrescentado. Lisboa: Typographia Lacerdina, 1813, p. 693.

SOUZA, George F. Cabral de. Tratos e mofatras: o grupo mercantil do Recife colonial, c. 1654-c.1759. Recife: Ed. Universitária da UFPE, 2012. 